\title{
A new Machine Learning based Deep Performance Index for Ranking IPL T20 Cricketers
}

\author{
C. Deep Prakash \\ Deptt. Of Electrical Engg. \\ Dayalbagh Educational Institute \\ Agra-282005, India
}

\author{
C. Patvardhan \\ Deptt. Of Electrical Engg. \\ Dayalbagh Educational Institute \\ Agrs-282005,India
}

\author{
Sushobhit Singh \\ Deptt. Of Electrical Engg. \\ Dayalbagh Educational Institute \\ Agra-282005,India
}

\begin{abstract}
T20 cricket has brought about a revolution in cricket. The Indian Premier League (IPL) tournament organized every year by the Board of Cricket Control of India has become very popular with a huge fan following. It is based on franchises bidding for acquiring players to play for their side. Huge amounts of money are involved in the auction. Ranking of players in IPL according to their performance is an important step that would allow franchises and team managers to take better informed decisions in choosing their sides. In this paper, a machine learning based approach is used to create a new index, named as Deep Performance Index (DPI), that reflects the performance of the batsmen and bowlers on a deeper analysis of the requirements of T20 cricket. The Recursive Feature elimination algorithm based on machine learning is used for extracting meaningful features and their relative importance towards designing the DPI. It is shown that DPI is able to better capture performance related data for both batsmen and bowlers when compared to some other well-known ranking schemes for T20 cricket.
\end{abstract}

\section{General Terms}

Machine Learning, Cricket, Player Ranking, Algorithms

\section{Keywords}

IPL, Cricket, T20, Performance Index, Player Evaluation

\section{INTRODUCTION}

Cricket is a popular game these days. It is played in more than 50 countries at various levels. T20 is a 20 overs a side match which is usually over in 4 hours.

The game of cricket got a new dimension when the Indian Premier League (IPL), a T20 tournament was started in 2008 by Board of Control of Cricket in India (BCCI) [1]. Eight franchises were created and assigned to eight of the largest cities in India. The teams were franchisee driven. The players were selected through competitive bidding from a pool of available players. The BCCI has been organizing the IPL T20 cricket tournament every year. There have been 8 IPL tournaments till date and the $9^{\text {th }}$ edition in scheduled to be held beginning in April, 2016.

Cricket is a sport in which statistics feature heavily and these statistics give clear picture of each and every facet of cricket. Followers of the game, especially in India, are keen followers of its statistics also. Some studies related to cricket reported in the literature are as follows. Optimal batting strategies using dynamic programming model were developed by Clarke [2]. Alternative batting averages when the batsman remains not-out in one-day cricket was proposed by Kimber and Hansford [3] and Damodaran [4]. Barr and Kantor [5] proposed a method based on batting averages and strike rates. Borooah and Mangan [6] explored batting performance for test matches. Norman and Clark [7] and Ovens and Bukeit
[8] applied mathematical modeling approach to optimize the batting order of a team. Lewis [9] analyzed player performance using Duckworth/Lewis percentage values. Van Staden [10] used a graphical method to analyze batting and bowling performance in cricket. Lakkaraju and Sethi [11] described a Sabermetrics style principle to analyze batting performance in cricket. Lemmer [12-14] considered performance analysis using averages and strike rates for bowling and batting. Saikia et al. [15] evaluated the performance of all-rounders in IPL. Several efforts have been reported in the literature related to players performance in IPL and their valuation in auction [16-18] recently.

In this paper, a machine learning based approach is used to create a new index, named as Deep Performance Index (DPI), that reflects the performance of the batsmen and bowlers in T20 cricket based on a deeper analysis of the requirements of T20 cricket. The Recursive Feature elimination algorithm in machine learning is used for extracting the meaningful features and their relative importance towards designing the DPI. It is shown that the DPI is better able to capture the performance related data for both batsmen and bowlers when compared to some other well-known ranking schemes for T20 cricket.

In this work, IPL performance data upto IPL 7 and the overall T20 career data upto the end of IPL 8 has been collected for all the players participating in IPL [8]. Only those batsmen who have scored more than 500 runs in T20 internationals with Strike Rate more than 100 and played in at least 25 matches are considered for ranking based on batting. A total of 89 batsmen satisfy these criteria and are included in this effort. Similarly, only those bowlers who played in IPL 8 and have bowled more than 30 overs in their T20 international careers are considered for ranking as bowlers. Thus, a total of 120 bowlers are considered.

The rest of the paper is organized as follows. Some prevailing metrics for evaluating players' performance in cricket are reviewed in section 2 along with their limitations and strengths. The special features of T20 cricket and the metrics considered in this work specifically for T20 are presented in section 3. The Random Forests approach and the new metrics evolved using this machine learning approach are presented in section 4. Some results and discussion are presented in section 5 . The conclusions of the work and some pointers to future work are presented in section 6 .

\section{POPULAR INDICES FOR T20 PLAYERS EVALUATION}

The popularity of T20 has motivated several efforts to identify meaningful indices for evaluating performance of batsmen and bowlers. In this section the main reported attempts are described. The notation used to describe the indices is as given in Table 1. 
Table 1: Notation for describing metrics for performance evaluation of $\mathrm{T} 20$ players

\begin{tabular}{|c|c|c|c|}
\hline$\#$ & Acronym & Expansion & Formula \\
\hline 1 & PRS & $\begin{array}{lll}\begin{array}{l}\text { Runs } \\
\text { Player }\end{array} & \text { Scored } & \text { by } \\
\end{array}$ & \\
\hline & TRS & $\begin{array}{l}\text { Runs scored in } \\
\text { Tournament }\end{array}$ & \\
\hline 2 & PBA & $\begin{array}{ll}\text { Player } & \text { Batting } \\
\text { Average } & \end{array}$ & $\begin{array}{l}\text { PRS / Number of times } \\
\text { out }\end{array}$ \\
\hline 3 & TBA & $\begin{array}{l}\text { Tournament Batting } \\
\text { Average }\end{array}$ & $\begin{array}{l}\text { TRS / Total wickets } \\
\text { fallen }\end{array}$ \\
\hline 4 & PBSR & $\begin{array}{l}\text { Player Batting Strike } \\
\text { Rate }\end{array}$ & $\begin{array}{l}\text { PRS / Balls Faced by } \\
\text { Player }\end{array}$ \\
\hline 5 & TBSR & $\begin{array}{l}\text { Tournament Batting } \\
\text { Strike Rate }\end{array}$ & $\begin{array}{l}\text { TRS / Balls Faced in } \\
\text { Tournament }\end{array}$ \\
\hline 6 & PWT & Player Wickets Taken & \\
\hline 7 & TWT & $\begin{array}{l}\text { Tournament Wickets } \\
\text { Taken }\end{array}$ & \\
\hline 8 & PBB & $\begin{array}{l}\text { Number of } \\
\text { Bowled }\end{array}$ & \\
\hline 9 & TBB & $\begin{array}{ll}\text { Tournament } & \text { Balls } \\
\text { Bowled } & \\
\end{array}$ & \\
\hline 10 & PRC & $\begin{array}{ll}\text { Player } & \text { Runs } \\
\text { Conceded } & \\
\end{array}$ & \\
\hline 11 & TRC & $\begin{array}{ll}\begin{array}{l}\text { Tournament } \\
\text { conceded }\end{array} & \text { Runs } \\
\end{array}$ & \\
\hline 12 & PBWA & $\begin{array}{ll}\text { Player } & \text { Bowling } \\
\text { Average } & \end{array}$ & $\mathrm{PBB} / \mathrm{PWT}$ \\
\hline 13 & TBWA & $\begin{array}{l}\text { Tournament Bowling } \\
\text { Average }\end{array}$ & TBB/TWT \\
\hline 14 & PBWER & $\begin{array}{l}\text { Player Bowling } \\
\text { Economy Rate }\end{array}$ & $(\mathrm{PRC} * 6) / \mathrm{PBB}$ \\
\hline 15 & TBWER & $\begin{array}{l}\text { Tournament Bowling } \\
\text { Economy Rate }\end{array}$ & $\left(\mathrm{TRC}^{*} 6\right) / \mathrm{TBB}$ \\
\hline 16 & PBWSR & $\begin{array}{l}\text { Player Bowling Strike } \\
\text { Rate }\end{array}$ & $\mathrm{PRC} / \mathrm{PWT}$ \\
\hline 17 & TBWSR & $\begin{array}{l}\text { Tournament } \text { Bowler } \\
\text { Strike Rate }\end{array}$ & TRC/TWT \\
\hline 18 & Fours & $\begin{array}{l}\begin{array}{l}\text { Number of fours } \\
\text { scored }\end{array} \\
\end{array}$ & \\
\hline 19 & Sixes & $\begin{array}{l}\text { Number of sixes } \\
\text { scored }\end{array}$ & \\
\hline 20 & $\mathrm{HF}$ & $\begin{array}{l}\text { Sum total of number } \\
\text { of centuries and half } \\
\text { centuries scored }\end{array}$ & \\
\hline
\end{tabular}

In this work, both overall T20 career data of the players (http://www.espncricinfo.com) [16] as well as their IPL career data (www.iplT20.com) [17] are taken into consideration. The often quoted index in the case of IPL is the Most Valuable Player Index (MVPI) popularized by Rediff Cricket [16]. MVPI for batsmen and bowlers is defined as follows.

$$
\text { Batting }=[(\mathrm{PBA} / \mathrm{TBA}) * \mathrm{PRS}+(\mathrm{PBSR} / \mathrm{TBSR})] * \mathrm{PRS}
$$$$
\text { Bowling }=\left[(\text { TBWA/PBWA })+(\text { TBWER/PBWER })^{2}\right] * \text { PWT }
$$

The MVPI for a player is the sum of his batting points and bowling points. Fielding points are not considered in the present work. Amit Kumar and Sindhu [19] use a variety of detailed metrics to analyze batting performance in IPL. The metrics are designed to reflect individual match situations and the impact of the player's performance on the match outcome. However, detailed data that is necessary to calculate the values is not available easily. Dey and Ghosh [20] employ an MCDM approach for evaluating Bowlers performance in IPL.
They propose the following composite index for comparing Bowlers performance

$\mathrm{MCDM}=0.0522 *$ Matches $+0.0651 *(\mathrm{PBB} / 6)+0.149 *$ $\mathrm{PWT}+0.2575 * \mathrm{PBWA}+0.2107 * \mathrm{PBWSR}+0.2655 *$ PBWER.

Almost 25\% weightage is given to indices (matches, overs and wickets) that are a function of how long the player has been in international cricket. Rastogi and Deodhar [21] utilize an extended list of parameters in evaluating Player pricing and attributes in the Twenty20 scenario. Manage and Scariano [22] utilize Principal Components Analysis to determine composite indices for evaluating the performance of batsmen and bowlers in IPL 2012. The indices are as follows:

PCA (batsmen) $=0.458 * \mathrm{PRS}+0.398 * \mathrm{PBA}+0.325 *$ PBSR $+0.406 *$ Fours $+0.417 *$ Sixes $+0.432 *$ HF

Higher values indicate better performance. PCA Index for batsmen assigns almost equal weightages to total number of runs scored through the career, average, strike rate, fours, sixes and centuries or half centuries. The range of weights is quite small and so relative impact of the indices is not very prominent. However, the absolute values of the metrics are widely different i.e. a player could have scored many boundaries whereas the number of centuries and half centuries would be relatively very small.

PCA (bowlers) $=-0.428 *$ PWT $+0.591 *$ PBWA $+0.383 *$ PBWER + $0.566 *$ PBWSR

In case of bowlers, smaller values indicate better performance in the PCA as shown. However, in this paper the -ve of this index is taken for easier comparison and so larger values indicate better performance. PCA Index for bowlers assigns almost equal weightages to number of wickets taken through the career and the average, economy and strike rate indices. In the PCA indices the absolute values of some parameters i.e. wickets and strike rate would be much larger than the others e.g. economy. Michael Hussey [23] defined a very simple index to rate a batsman's performance in Twenty 20 .

Hussey's Batting Score or Hussey Index = PBSR+ PBA

Any value above 160 is considered by Hussey as good.

The above metrics provide an overall picture of the performance but are typically biased towards players who have played more. MVPI is calculated considering the complete career data of T20 using the formula given by Rediff Cricket for the batsmen shortlisted according to the above criteria. The list of top ten Batsman according to MVPI Ranking is shown in Table 2. Chris Gayle, as per popular belief, is way ahead of the others in this ranking.

Table 2: Top 10 Batsmen according to MVPI ranking

\begin{tabular}{|l|l|}
\hline Player & MVPI \\
\hline Chris Gayle & 24974.16 \\
\hline Kieron Pollard & 15218.57 \\
\hline Brendon Mccullum & 15036.85 \\
\hline David Warner & 14594.05 \\
\hline Suresh Raina & 13819.02 \\
\hline Rohit Sharma & 12064.45 \\
\hline Ryan ten Doeschate & 11989.73 \\
\hline Virat Kohli & 11427.18 \\
\hline JP Duminy & 11320.57 \\
\hline MS Dhoni & 11151.54 \\
\hline
\end{tabular}


MVPI ranking is computed for all the bowlers shortlisted as above. The top ten Bowlers according to MVPI Ranking are as shown in Table 3.

Table 3: Top 10 Bowlers according to MVPI ranking

\begin{tabular}{|l|l|}
\hline Player & MVPI \\
\hline Dwayne Bravo & 9325.68 \\
\hline Lasith Malinga & 8909.277 \\
\hline Azhar Mahmood & 7469.081 \\
\hline Kieron Pollard & 7137.99 \\
\hline Albie Morkel & 6137.999 \\
\hline Shakib Al Hasan & 4997.408 \\
\hline Sunil Naraine & 4980.51 \\
\hline Amit Mishra & 4972.211 \\
\hline James Faulkner & 4486.795 \\
\hline Morne Morkel & 4400.002 \\
\hline
\end{tabular}

The main limitation with MVPI is that, in MVPI, the runs scored by a batsman and the wickets taken by a bowler dominate its value. There are other parameters also which have to be taken care of otherwise only the top order batsman will come out top in the list because the number of balls they get to play is usually much more than the finishers and so they get to score more runs. Those who accomplish great finishes will never get a chance to top the MVPI list. Similar is the case with bowlers who have bowled economically throughout the tournament but did not get many wickets they will never get a chance to top the MVPI list. However, these could be the bowlers who made the batsman to go after the other bowlers and made them loose their wickets and so their efforts cannot be undermined. These points highlight the need for developing other metrics that are more relevant to T20 cricket in particular.

\section{METRICS PROPOSED AND UTILIZED IN THIS WORK}

T20 cricket has altered the game of cricket completely. Most of the points of difference do stem from the fact that the T20 version is a shortened version of the game of cricket. But a deeper analysis and understanding is necessary to really appreciate the level of impact that this change brings into the game. Some of the important points in this respect are as follows.

(i) Since the number of balls available is less it is important to make each ball count.

(ii) One loose ball in an otherwise perfect over is enough to take the pressure off the batsmen. Margin of error is, therefore, very small for bowlers.

(iii) One good wicket-taking ball or even a couple of dot balls at a crucial stage can trigger a panic causing batsman to take suicidal risk.

(iv) Bowling in the so called "death overs" is a bowler's nightmare. The margin of error becomes even smaller.

(v) Risk takers with talent for doing so in both batting and bowling are more necessary in T20.

Therefore, new metrics need to be developed. These additional considerations need to be incorporated fully in the newer metrics designed to find out which batsmen and which bowlers are the real performers in T20. Selected indices are extracted from the raw data available to calculate the ranking of the players. Care is taken to ensure that the indices designed also give a fair chance to upcoming players. Some new indices and a new comprehensive index based on the indices for calculating the ranks of the players are proposed in this work.

In order to evaluate the batting capability in T20, five indices are considered as follows.

1) HardHitter $=(4 *$ Fours $+6 *$ Sixes $) /$ Balls faced by player

Hard Hitter Score is useful in T20 because players who can score more boundaries in their innings so that they give big boost to the scoreboard as well as create psychological pressure on the bowler are desirable.

2) Finisher $=$ Number of times Not Out/ Total number of played Innings

Finisher Score is useful because we want the batsman to remain not out and guide the innings till the end. In any T20 match the last 2-3 overs are really crucial.

\section{3) FastScorer (PBSR)}

A T20 batsman has to be a Fast Scorer.

\section{4) Consistent (PBA)}

A consistent scorer is one with a good average.

5) RunningBetweenWickets $($ RBW $)=($ PRS $-(4 *$ Fours $+6 *$ Sixes) $) /$ Number of balls faced without boundary

Running Between Wickets Score is important because the batsmen have to ensure that the score board keeps ticking even when the boundaries are hard to get. Rotating strike makes it difficult for a bowler to settle into a good rhythm.

The above five measures are typical T20 measures and provide a more detailed analysis of the performance of the batsmen. Similarly, in order to define Bowling Capability five indices are considered as follows.

\section{1) $\operatorname{Economy}(\mathbf{P B W E R})=\mathrm{PRC} /(\mathrm{PBB} / 6)$}

Economy Score is important because every team wants its bowlers to concede minimum runs. From one end when a bowler bowls economically he can create opportunities for taking wickets for the other bowler.

\section{2) WicketTaker $($ PBWA $)=$ PBB $/$ PWT}

Wicket Taker Score is useful because the bowlers who take important wickets or take wickets at crucial junctures in the match win the match for their team. In T20, after every wicket there is a huge impact on the game especially in the first five and the last five overs.

\section{3) Consistent $($ PBWSR $)=$ PRC $/$ PWT}

Consistent Score is useful because every team wants their bowlers to perform in every match.

4) BigWicketTaker $=$ Number of times four wickets or five wickets taken / Number of innings played

Big Wicket Taking Score is useful because this attribute shows how much impact that bowler can have in a match or in other words, how many matches he can win for his team on the strength of his bowling alone almost single handedly. 
5) ShortPerformance $=\left(\right.$ Number of wickets taken $-4^{*}$ Number of times four wickets $-5^{*}$ Number of times five wickets taken) / (Number of innings played Number of times four wickets or five wickets taken)

Short Performance Score is important because sometimes a good spell can change the result of the match.

These indices are calculated considering the first seven (2008-2014) seasons of IPL data and Overall T20 Career data of the players upto IPL 8 considering the same 89 batsmen and 120 bowlers as above (in case of MVPI calculations). Some players who have played international games in T20 but not played in IPL have 0s against their names in IPL metrics. Table 4 shows the sample values of ten indices for the batsmen in alphabetical order and their MVPIs. Table 5 shows sample values of the ten indices for some bowlers in alphabetical order and their MVPIs.

An aggregate function of the 10 indices is required to calculate the actual Ranking of a batsman or a bowler. Since the ranges of absolute values of the indices are widely different, these are first normalized to lie within a range on 0 to 1 . This is done as follows.

- For each index, the list is sorted in descending order of preference i.e. best performer first i.e. the best performer has rank 1 with others following.

- Points for that particular index is calculated by

Points $=($ No of Players - Rank according to that particular feature)/ No of players

\section{MACHINE LEARNING APPROACH FOR SELECTING IMPORTANT FEATURES AND DETERMINING THEIR RELATIVE IMPORTANCE}

Ten indices were computed for each batsman and each bowler in the previous section. In the machine learning terminology these can be regarded as features for evaluating their T20 performance. However, when raw data is processed to get some predetermined features it is often the case that there is some strong correlation between some of features and keeping all of them is essentially redundant. One of them could actually suffice in such a case. It might also be the case that some of the so called features do not contribute significantly to the target performance index and actually act as noise. Therefore, it is important to weed out both these categories of features and only retain the significant ones. This is the task of features selection. The next task is to get a single feature for ranking the relative performance of the batsmen and another feature for ranking the bowlers. Some methodology might be used to determine the weightages for aggregation according to their relative importance. In order to find the 5 important indices the "Caret" package in $\mathrm{R}$ is used which provides features selection method based on the target variable and the assumed independent variables. In this work, the 10 indices computed in section 3 form the independent variables or $\mathrm{X}$ vector and the MVPI forms the target variable for variable selection.

The two tasks are accomplished in this work as follows.

Step 1: 5 indices that are more relevant to the target measure are selected as features out of the 10 indices computed for evaluating performance of batsmen and bowlers.

Step 2: The relative weightages of these features are also computed to obtain a weighted function that represents a comprehensive indices for evaluating T20 performance of batsmen and bowlers.

The algorithm utilized for this purpose is the Recursive Feature Elimination (RFE). First, the algorithm fits the model to all predictors which are the indices in the current work. Let $\mathrm{S}$ be a sequence of ordered numbers which are candidate values for the number of predictors to retain $(\mathrm{S} 1>\mathrm{S} 2, \ldots)$. At each iteration of feature selection, the $S_{\mathrm{i}}$ top ranked predictors are retained, the model is refit and performance is assessed. The value of $S_{i}$ with the best performance is determined and the top $S_{i}$ predictors are used to fit the final model.

The predictor rankings are recomputed on the model on the reduced feature set. 10-fold cross-estimation is performed and a ranking procedure is employed to complete the selection process. The 5 indices selected for Batting and Bowling are shown in Table 6 along with their relative importance as determined by this approach.

\section{PROPOSED PERFORMANCE RANKING SCHEME}

The performance of batsmen and bowlers is ranked according to weighted average of the 5 indices according to the weights selected in section 4. The weighted average is used for determining the rank. This index is named Deep Performance Index (DPI) in this paper highlighting the fact that the index is based on a deeper analysis of the requirements of T20 cricket (and of course, the name of the author). A new performance ranking for Batsmen and Bowlers is thus obtained. The top 10 batsmen according to this DPI ranking are shown in Table 7 along with the top 10 batsmen according to some other notable schemes including the most commonly employed MVPI. Table 8 shows the values of the 5 individual performance indices and the corresponding DP index calculated from them in this paper along with the values of the other performance indices i.e. MVPI, Hussey Index and PCA index for each of the batsmen appearing in Table 7. Some observations from tables 7 and 8 are as follows:

(i) Chris Gayle is ranked number 1 according to all the four schemes confirming his towering stature as a top T20 batsman.

(ii) David Miller and Shaun Marsh are players to watch for in future. This is reflected in their consistent performances and, therefore, in DPI. However, the other indices do not capture the impact of their consistency adequately.

(iii) PCA Ranking ranks David Warner higher than both MS Dhoni as well as Suresh Raina although the latter two are more consistent in their performance and also have higher strike rates. Thus, they are rated higher by DPI. Similar is the case of K Pollard as a batsman. K Pollard, of course, has utility as an allrounder too.

(iv) Glenn Maxwell, Andre Russel and Ben Cutting make it to the top 10 according to Hussey index primarily because of their high strike rate. However, they do not figure in any of the other lists because they are not consistent. Conversely, Duminy is extremely consistent whether overall T20 career record is considered or only IPL record is considered. However, he loses out on fast scoring desired in T20. Thus DPI is able identify the batsmen who are performers according to all the indices. 
(v) 4 of the top 10 batsmen in DPI ranking do not appear in any of the other top 10 lists. These are Shaun Marsh, Kevin Peterson, AB de Villiers and Shane Watson. Although the other indices fail in identifying these doyens, DPI is able to do it.

The top 10 bowlers according to this DPI ranking are shown in Table 9 along with the top 10 bowlers according to some other notable schemes including the most commonly employed MVPI. The corresponding values are shown in Table 10. Some important observations from these tables are as follows.

(i) Lasith Malinga continues to be at the top according to DPI as he is according to the other indices.

(ii) Shakib Hassan also ranks high because of his wicket taking capabilities that are important in T20 also.

(iii) However, Dwayne Bravo does not appear in top 10 according to DPI because his performance is not good according to metrics identified in this work.

(iv) Similarly, K Pollard appears in all the other lists but in terms of the metrics identified in this work he does not appear to be a good performer. He neither ranks highly in wicket taking nor in consistency as a bowler. Albie Morkel's case is also similar.

(v) DPI throws up some new bowlers such as S Arvind, Sandeep Sharma, Mohit Sharma and Parvinder Awana who are not identified in any of the other metric. However, they are ranked quite high in terms of the metrics identified in this work and are the players to watch for.

\section{CONCLUSIONS AND FUTURE WORK}

The proposed DPI Ranking scheme clearly shows some of the emerging talents in the top ten which would never be the case with MVP index. They would not get a chance to be counted when compared to the long time cricketing legends. However, in DPI scheme the names of rising stars clearly show that they are the future of cricketing world. Such an analysis clearly is of benefit to the franchises who can determine the players with higher return of investment potential.

Details can be enhanced with categorization of players according to their perceived roles in the playing XI. This is being pursued. The analysis can further be extended to develop an optimization procedure for selection of playing XI.

\section{REFERENCES} [1] Indian Premier $\quad$ League,

[2] Clarke, S R, "Dynamic programming in one day cricket optimal scoring rates," Journal of the Operational Research Society, 50, 1988, pp 536 - 545.

[3] Kimber, A C and Hansford, A R, "A Statistical Analysis of Batting in Cricket," Journal of Royal Statistical Society, 156, 1993, pp $443-455$.

[4] Damodaran, U, "Stochastic Dominance and Analysis of ODI Batting Performance: The Indian Cricket Team, 1989-2005," Journal of Sports Science and Medicine, 5, 2006, pp $503-508$.

[5] Barr, G. D. I., and Kantor, B.S., "A Criterion for Comparing and Selecting Batsmen in Limited Overs
Cricket," Journal of the Operational Research Society, 55, 2004, pp 1266-1274.

[6] Borooah, V. K., and Mangan, J E, "The 'Bradman Class': An Exploration of Some Issues in the Evaluation of Batsmen for Test Matches, 1877-2006.”, Journal of Quantitative Analysis in Sports, 6 (3), Article 14, 2010.

[7] Norman, J and Clarke, S R, "Dynamic programming in cricket: Batting on sticky wicket," Proceedings of the 7th Australasian Conference on Mathematics and Computers in Sport, 2004, pp $226-232$.

[8] Ovens, $\mathrm{M}$ and Bukeit, B, "A mathematical modeling approach to one day cricket batting orders," Journal of Sports Science and Medicine, 5, 2006, pp 495-502.

[9] Lewis, A., "Extending the Range of Player-Performance Measures in One-Day Cricket," Journal of Operational Research Society, 59, 2008, pp 729-742.

[10] Van Staden, P., "Comparison of Cricketers' Bowling and Batting Performance using Graphical Displays," Current Science, 96, 2009, pp 764-766.

[11] Lakkaraju, P., and Sethi, S., "Correlating the Analysis of Opinionated Texts Using SAS® Text Analytics with Application of Sabermetrics to Cricket Statistics," Proceedings of SAS Global Forum 2012, 136-2012, pp $1-10$.

[12] Lemmer, H., "A Measure for the Batting performance of Cricket Players," South African Journal for Research in Sport, Physical Education and Recreation, 26, 2004, pp 55-64

[13] Lemmer, H., "An Analysis of Players' Performances in the First Cricket Twenty20 World Cup Series," South African Journal for Research in Sport, Physical Education and Recreation 30, 2008, pp 71-77.

[14] Lemmer, H., "The Single Match Approach to Strike Rate Adjustments in Batting Performance Measures in Cricket," Journal of Sports Science and Medicine, 10, 2012, pp 630-634.

[15] Saikia, Hemanta and Bhattacharjee Dibojyoti, "A Bayesian Classification Model for Predicting the Performance of All-Rounders in the Indian Premier League,

http://papers.ssrn.com/sol3/papers.cfm?abstract_id=1622 060.

[16] http://www.espncricinfo.com/india/content/player/28081 html, T20 statistics of each player

[17] http://www.iplt20.com/teams/royal-challengersbangalore/squad/236/chris-gayle , IPL statistics of each player

[18] http://www.rediff.com/cricket/report/icc-world-cup-devilliers-maintains-big-lead-shami-rises-to-7th-in-mostvaluable-player-table/20150320.htm

[19] Amit Kumar and Ritu Sindhu, "Reflection against perception: Data Analysis of IPL Batsmen", International Journal of Engineering Science Invention, Vol. 3, Issue 6, June 2014, pp 7 - 11. ISSN No. 2319-6734.

[20] Ahmad F, Kalyanmoy Deb and Abhilash Jindal, "Multiobjective Optimization and decision making approaches to cricket team selection", Applied Soft Computing, Vol 13, 2013, pp $402-414$. 
[21] Dey PK and Ghosh DN, "An MCDM approach for evaluating Bowlers performance in IPL", Journal of emerging trends in Computing and Information Sciences, Vol 2, No. 11,November, 2011, ISSN 2079-8407, pp 663-573

\section{APPENDIX}

Table 4: Sample values of indices for some batsmen in alphabetical order

\begin{tabular}{|c|c|c|c|c|c|c|c|c|c|c|c|}
\hline Player & $\begin{array}{l}\text { T20_ } \\
\text { Cons } \\
\text { istent } \\
\end{array}$ & $\begin{array}{l}\text { T20_Fas } \\
\text { tScorer }\end{array}$ & $\begin{array}{l}\text { T20_ } \\
\text { Finisher }\end{array}$ & $\begin{array}{l}\text { T20_ } \\
\text { Hard } \\
\text { Hitter }\end{array}$ & $\begin{array}{l}\text { T20 } \\
\text { RBW }\end{array}$ & $\begin{array}{l}\text { IPL_ } \\
\text { Fast } \\
\text { Scorer }\end{array}$ & $\begin{array}{l}\text { IPL_- } \\
\text { Consis } \\
\text { Tent }\end{array}$ & $\begin{array}{l}\text { IPL_- } \\
\text { Fini } \\
\text { sher }\end{array}$ & $\begin{array}{l}\text { IPL } \\
\text { Hard } \\
\text { Hitter }\end{array}$ & $\begin{array}{l}\text { IPL } \\
\text { RBW }\end{array}$ & $\begin{array}{l}\text { MVP } \\
\text { Index }\end{array}$ \\
\hline AB de Villiers & 31.15 & 139.65 & 0.198 & 0.792 & 0.729 & 138.892 & 34.864 & 0.253 & 0.754 & 0.756 & 10116 \\
\hline Abhishek Nayar & 19.59 & 120.22 & 0.217 & 0.663 & 0.628 & 116.464 & 17.684 & 0.24 & 0.589 & 0.661 & 1717 \\
\hline A Tare & 23.97 & 125.52 & 0.148 & 0.777 & 0.579 & 137.156 & 17.588 & 0.190 & 0.944 & 0.540 & 1793 \\
\hline Ajinkya Rahane & 29.8 & 117.69 & 0.103 & 0.616 & 0.653 & 116.549 & 30.648 & 0.129 & 0.623 & 0.633 & 6127 \\
\hline Albie Morkel & 25.64 & 138.49 & 0.360 & 0.833 & 0.663 & 142.483 & 22.947 & 0.406 & 0.839 & 0.703 & 7793 \\
\hline Ambati Rayudu & 24.35 & 123.22 & 0.148 & 0.652 & 0.677 & 125.183 & 26.718 & 0.157 & 0.655 & 0.698 & 5179 \\
\hline Angelo Mathews & 25.04 & 122.08 & 0.276 & 0.566 & 0.745 & 123.423 & 24.909 & 0.266 & 0.567 & 0.755 & 3770 \\
\hline Azhar Mahmood & 25.35 & 135.16 & 0.212 & 0.779 & 0.691 & 129.054 & 21.222 & 0.1 & 0.777 & 0.620 & 8362 \\
\hline B Mcculum & 32.53 & 137.25 & 0.101 & 0.904 & 0.58 & 122.778 & 28.344 & 0.064 & 0.775 & 0.544 & 15037 \\
\hline Chris Gayle & 44.21 & 149.25 & 0.146 & 1.102 & 0.501 & 154.566 & 47.508 & 0.149 & 1.166 & 0.496 & 24974 \\
\hline
\end{tabular}

Table 5: Sample values of indices for some bowlers in alphabetical order

\begin{tabular}{|l|l|l|l|l|l|l|l|l|l|l|l|}
\hline & $\begin{array}{l}\text { T20_- } \\
\text { Econ } \\
\text { omy }\end{array}$ & $\begin{array}{l}\text { T20_- } \\
\text { Wicket } \\
\text { Taker }\end{array}$ & $\begin{array}{l}\text { T20_ } \\
\text { Consi } \\
\text { sten }\end{array}$ & $\begin{array}{l}\text { T20_Big } \\
\text { Wicket } \\
\text { Taker }\end{array}$ & $\begin{array}{l}\text { T20_ } \\
\text { ShortP } \\
\text { erform } \\
\text { ance }\end{array}$ & $\begin{array}{l}\text { IPL_ } \\
\text { Econo } \\
\text { my }\end{array}$ & $\begin{array}{l}\text { IPL_ } \\
\text { Wicket } \\
\text { Taker }\end{array}$ & $\begin{array}{l}\text { IPL_- } \\
\text { Consis } \\
\text { tent }\end{array}$ & $\begin{array}{l}\text { IPL_ } \\
\text { Big } \\
\text { Wicket } \\
\text { Taker }\end{array}$ & $\begin{array}{l}\text { IPL_ } \\
\text { Short } \\
\text { Perfor } \\
\text { mance }\end{array}$ & $\begin{array}{l}\text { MVP } \\
\text { Index }\end{array}$ \\
\hline A Mithun & 8.5 & 21 & 29.88 & 0.025 & 0.769 & 9.833 & 41.142 & 67.428 & 0 & 0.437 & 1038 \\
\hline A Nayar & 8.64 & 25.5 & 36.81 & 0 & 0.5 & 8.451 & 25.4 & 35.777 & 0 & 0.473 & 399 \\
\hline Abu Nechim & 7.83 & 22.7 & 29.69 & 0.021 & 0.820 & 7.543 & 23.2 & 29.166 & 0 & 0.857 & 1068 \\
\hline Albie Morkel & 7.7 & 20.5 & 26.39 & 0.011 & 0.843 & 8.097 & 20.227 & 27.3 & 0.012 & 0.95 & 6138 \\
\hline Amit Mishra & 7 & 18.2 & 21.32 & 0.026 & 1.082 & 7.207 & 18.476 & 22.196 & 0.034 & 1.072 & 4972 \\
\hline A Russell & 8.3 & 23.1 & 32.07 & 0.027 & 0.652 & 10.035 & 84 & 140.5 & 0 & 0.222 & 2854 \\
\hline A Mathews & 7.36 & 24.3 & 29.9 & 0.009 & 0.686 & 8.051 & 28.95 & 38.85 & 0.031 & 0.516 & 1667 \\
\hline Ankit Sharma & 7.27 & 23.8 & 28.89 & 0 & 0.783 & 6.598 & 25.575 & 28.125 & 0 & 0.667 & 658 \\
\hline Ashish Nehra & 7.7 & 17.5 & 22.6 & 0.021 & 1.182 & 7.913 & 18.671 & 24.626 & 0 & 1.155 & 3813 \\
\hline Ashish Reddy & 7.77 & 15.4 & 20 & 0.021 & 1.066 & 9.016 & 14.0769 & 21.153 & 0 & 1 & 1913 \\
\hline
\end{tabular}

Table 6: Relative importance of the top 5 performance indices for Batting and bowling

\begin{tabular}{|l|l|l|l|l|l|}
\hline $\begin{array}{l}\text { Batting } \\
\text { Features }\end{array}$ & $\begin{array}{l}\text { Relative Importance } \\
\text { as determined by } \\
\text { RFE }\end{array}$ & $\begin{array}{l}\text { Relative } \\
\text { weightage }\end{array}$ & Bowling Features & $\begin{array}{l}\text { Relative Importance } \\
\text { as determined by } \\
\text { RFE }\end{array}$ & $\begin{array}{l}\text { Relative } \\
\text { Weightage }\end{array}$ \\
\hline T20_Consistent & 33.2824 & 0.471 & IPL_ShortPerformance & 18.457 & 0.3486 \\
\hline IPL_Consistent & 13.7837 & 0.195 & T20_BigWicketTaker & 15.441 & 0.2916 \\
\hline IPL_FastScorer & 8.3443 & 0.118 & T20_Consistent & 7.718 & 0.1457 \\
\hline IPL_HardHitter & 7.7019 & 0.109 & IPL_WicketTaker & 6.064 & 0.1145 \\
\hline T20_FastScorer & 7.5683 & 0.107 & T20_ShortPerformance & 5.261 & 0.993 \\
\hline
\end{tabular}

Table 7: Comparison of results obtained from various Batting Ranking Schemes

\begin{tabular}{|c|l|l|l|l|}
\hline Rank & DPI & MVPI [21] & HusseyIndex [29] & PCA [25] \\
\hline 1 & Chris Gayle & Chris Gayle & Chris Gayle & Chris Gayle \\
\hline 2 & David Miller & K. Pollard & Andre Russel & B. Mccullum \\
\hline 3 & Shaun Marsh & B. Mccullum & Kieron Pollard & D. Warner \\
\hline 4 & MS Dhoni & D. Warner & Glen Maxwell & K. Pollard \\
\hline 5 & Suresh Raina & Suresh Raina & Ben Cutting & Suresh Raina \\
\hline
\end{tabular}




\begin{tabular}{|c|l|l|l|l|}
\hline 6 & K. Peterson & Rohit Sharma & David Miller & D. Smith \\
\hline 7 & D. Warner & R. Doeschate & David Warner & R. Sharma \\
\hline 8 & S. Watson & Virat Kohli & V. Sehwag & R. Doeschate \\
\hline 9 & K. Pollard & JP Duminy & David Wiese & Virat Kohli \\
\hline 10 & AB De Villiers & MS Dhoni & Yusuf Pathan & G. Gambhir \\
\hline
\end{tabular}

Table 8: Values of Deep Performance Index and various popular indices for top T20 batsmen

\begin{tabular}{|c|c|c|c|c|c|c|c|c|c|}
\hline Player & $\begin{array}{l}\text { DPI } \\
\text { Rank }\end{array}$ & $\begin{array}{l}\mathrm{T} 20_{-} \\
\text {Consistent }\end{array}$ & $\begin{array}{l}\mathrm{IPL}_{-} \\
\text {Consistent }\end{array}$ & $\begin{array}{l}\text { IPL_ } \\
\text { Fast } \\
\text { Scorer }\end{array}$ & $\begin{array}{l}\text { IPL_ } \\
\text { Hard } \\
\text { Hitter }\end{array}$ & $\begin{array}{l}\text { T20_ } \\
\text { Fast } \\
\text { Scorer }\end{array}$ & $\begin{array}{l}\text { DP } \\
\text { Index }\end{array}$ & $\begin{array}{l}\text { Hussey } \\
\text { Index }\end{array}$ & $\begin{array}{l}\text { PCA } \\
\text { Index }\end{array}$ \\
\hline Chris Gayle & 1 & 1 & 0.988 & 0.977 & 0.988 & 0.932 & 0.986 & 193.459 & 4352.75 \\
\hline David Miller & 2 & 0.977 & 1 & 0.955 & 0.887 & 0.808 & 0.951 & 176.510 & 2083.17 \\
\hline Shaun Marsh & 3 & 0.988 & 0.977 & 0.752 & 0.764 & 0.584 & 0.890 & 170.97 & 2260.35 \\
\hline MS Dhoni & 4 & 0.943 & 0.966 & 0.876 & 0.707 & 0.719 & 0.890 & 172.09 & 2295.99 \\
\hline Suresh Raina & 5 & 0.898 & 0.910 & 0.865 & 0.797 & 0.842 & 0.879 & 174.269 & 2897.96 \\
\hline K. Peterson & 6 & 0.910 & 0.921 & 0.797 & 0.775 & 0.707 & 0.862 & 169.430 & 2024.41 \\
\hline David Warner & 7 & 0.887 & 0.842 & 0.775 & 0.853 & 0.876 & 0.860 & 175.76 & 3082.49 \\
\hline Shane Watson & 8 & 0.820 & 0.898 & 0.887 & 0.932 & 0.865 & 0.860 & 171.85 & 2183.26 \\
\hline K. Pollard & 9 & 0.831 & 0.662 & 0.910 & 0.898 & 0.955 & 0.828 & 184.47 & 3041.26 \\
\hline AB de Villiers & 10 & 0.808 & 0.887 & 0.831 & 0.696 & 0.831 & 0.816 & 170.799 & 2233.11 \\
\hline Rohit Sharma & 12 & 0.876 & 0.853 & 0.674 & 0.685 & 0.617 & 0.799 & 164.61 & 2724.59 \\
\hline Virat Kohli & 13 & 0.921 & 0.808 & 0.539 & 0.595 & 0.561 & 0.780 & 164.34 & 2530.04 \\
\hline JP Duminy & 14 & 0.966 & 0.943 & 0.505 & 0.325 & 0.314 & 0.767 & 159.85 & 2479.46 \\
\hline V. Sehwag & 15 & 0.640 & 0.707 & 0.988 & 0.977 & 0.921 & 0.761 & 175.46 & 2177.43 \\
\hline B. Mcculum & 16 & 0.853 & 0.685 & 0.483 & 0.719 & 0.775 & 0.753 & 169.78 & 3323.30 \\
\hline Yusuf Pathan & 17 & 0.651 & 0.651 & 0.932 & 0.943 & 0.910 & 0.744 & 174.87 & 1913.61 \\
\hline R Doeschate & 19 & 0.775 & 0.505 & 0.853 & 0.831 & 0.797 & 0.740 & 167.78 & 2695.60 \\
\hline Dwane Smith & 23 & 0.550 & 0.876 & 0.764 & 0.910 & 0.505 & 0.674 & 153.6 & 2891.19 \\
\hline G. Gambhir & 24 & 0.719 & 0.775 & 0.595 & 0.584 & 0.280 & 0.653 & 150.29 & 2500.67 \\
\hline G Maxwell & 31 & 0.224 & 0.820 & 1 & 1 & 0.988 & 0.598 & 176.98 & 1369.42 \\
\hline Andre Russell & 70 & 0.359 & 0.112 & 0.112 & 0.112 & 1 & 0.323 & 191.29 & 1199.94 \\
\hline Ben Cutting & 72 & 0.314 & 0.101 & 0.101 & 0.101 & 0.962 & 0.294 & 176.67 & 322.104 \\
\hline David Wiese & 82 & 0.146 & 0.044 & 0.044 & 0.044 & 0.977 & 0.192 & 175.44 & 512.644 \\
\hline
\end{tabular}

Table 9: Comparison of results obtained from Various Bowling Ranking Schemes

\begin{tabular}{|l|l|l|l|l|}
\hline Rank & DPI & MVPI [21] & PCA [25] & MCDM [24] \\
\hline 1 & Lasith Malinga & Dwayne Bravo & Lasith Malinga & Lasith Malinga \\
\hline 2 & Shakib Hasan & Lasith Malinga & Dwayne Bravo & Dwayne Bravo \\
\hline 3 & S. Arvind & Azhar Mahmood & Azhar Mahmood & Azhar Mahmood \\
\hline 4 & S. Narine & K. Pollard & S Narine & A Morkel \\
\hline 5 & Sandeep Sharma & Albie Morkel & Albie Morkel & K Pollard \\
\hline 6 & Mohit Sharma & Shakib Hasan & Kieron Pollard & Sunil Narine \\
\hline
\end{tabular}




\begin{tabular}{|l|l|l|l|l|}
\hline 7 & Imran Tahir & Sunil Narine & Shakib Hasan & H Singh \\
\hline 8 & P. Awana & Amit Mishra & Amit Mishra & Dale Steyn \\
\hline 9 & James Faulkner & James Faulkner & Dale Steyn & Shakib Hasan \\
\hline 10 & A. Mishra & Morne Morkel & R Ashwin & R Ashwin \\
\hline
\end{tabular}

Table 10: Values of Deep Performance Index and various popular indices for top T20 bowlers

\begin{tabular}{|c|c|c|c|c|c|c|c|c|c|}
\hline Player & $\begin{array}{l}\text { DPI } \\
\text { Rank }\end{array}$ & $\begin{array}{l}\text { IPL_ } \\
\text { Short } \\
\text { Perform } \\
\text { ance }\end{array}$ & $\begin{array}{l}\text { T20_ } \\
\text { Big } \\
\text { Wicket } \\
\text { Taker }\end{array}$ & $\begin{array}{l}\text { IPL_ } \\
\text { Wicket } \\
\text { Taker }\end{array}$ & $\begin{array}{l}\mathrm{T} 20_{-} \\
\text {Consis } \\
\text { tent }\end{array}$ & $\begin{array}{l}\text { T20_ } \\
\text { Short } \\
\text { Perfor } \\
\text { mance }\end{array}$ & $\begin{array}{l}\text { DP } \\
\text { Index }\end{array}$ & $\begin{array}{l}\text { MCDM } \\
\text { Index }\end{array}$ & $\begin{array}{l}\text { PCA } \\
\text { Index }\end{array}$ \\
\hline Lasith Malinga & 1 & 0.933 & 0.925 & 0.95 & 0.95 & 0.95 & 0.936 & 95.96 & 103.72 \\
\hline Shakib Hasan & 2 & 0.992 & 0.85 & 0.966 & 0.908 & 0.816 & 0.917 & 58.94 & 54.30 \\
\hline S Arvind & 3 & 0.958 & 0.958 & 0.983 & 0.783 & 0.716 & 0.911 & 7.584 & 1.65 \\
\hline Sunil Narine & 4 & 0.825 & 0.966 & 0.933 & 0.966 & 0.841 & 0.900 & 70.11 & 68.952 \\
\hline Sandeep Sharma & 5 & 1 & 0.658 & 1 & 0.825 & 0.916 & 0.866 & 7.839 & 2.05 \\
\hline Mohit Sharma & 6 & 0.95 & 0.8 & 0.958 & 0.65 & 0.758 & 0.844 & 14.59 & 5.09 \\
\hline Imran Tahir & 7 & 0.983 & 0.583 & 0.991 & 0.866 & 0.891 & 0.841 & 38.19 & 29.60 \\
\hline P Awana & 8 & 0.883 & 0.841 & 0.858 & 0.633 & 0.858 & 0.829 & 12.39 & 2.14 \\
\hline J Faulkner & 9 & 0.9 & 0.708 & 0.941 & 0.775 & 0.875 & 0.827 & 38.94 & 33.19 \\
\hline Amit Mishra & 10 & 0.875 & 0.717 & 0.875 & 0.841 & 0.808 & 0.817 & 55.49 & 49.31 \\
\hline Dwayne Bravo & 15 & 0.85 & 0.767 & 0.908 & 0.641 & 0.7 & 0.786 & 92.47 & 91.09 \\
\hline A Mahmood & 17 & 0.967 & 0.483 & 0.9 & 0.608 & 0.8 & 0.749 & 85.66 & 79.45 \\
\hline M Morkel & 18 & 0.817 & 0.758 & 0.691 & 0.575 & 0.741 & 0.742 & 51.82 & 40.54 \\
\hline Dale Steyn & 24 & 0.867 & 0.467 & 0.708 & 0.708 & 0.75 & 0.696 & 59.95 & 47.24 \\
\hline H Singh & 33 & 0.692 & 0.667 & 0.658 & 0.491 & 0.466 & 0.628 & 62.56 & 42.87 \\
\hline R Ashwin & 36 & 0.767 & 0.458 & 0.633 & 0.6 & 0.641 & 0.624 & 57.61 & 42.89 \\
\hline K Pollard & 46 & 0.55 & 0.55 & 0.8 & 0.7 & 0.416 & 0.587 & 72.89 & 64.48 \\
\hline A Morkel & 48 & 0.75 & 0.433 & 0.816 & 0.366 & 0.366 & 0.571 & 81.86 & 64.86 \\
\hline
\end{tabular}

